\title{
Changes in the School Curriculum in Albania
}

\section{Doi:10.5901/jesr.2014.v4n4p368}

\author{
Dr. Shqipe Haxhihyseni \\ Universitety "Aleksandaër Moisiu" Durrës \\ shqipeshyti@yahoo.com
}

\begin{abstract}
The organizing of schools, college and more further education has been associated with the ideas of the same sets of courses which the educational institution offers, called: the school curriculum. The curriculum can also be considered as the interaction of teachers, students and knowledge. In other words, curriculum is what actually happens in the classroom between the participants preparing orland evaluating. In Albania's schools, the curriculum changes very often and almost every year in the two last decades, something new is added, but soon it will be fundamentally reformulated, the biggest change being the making of the primary school 6 years and what should be middle school, 3 years, unlike now where the system is based on a 5 +4 years of pre high-school education. But will this change improve the quality of teaching? Should there be made any changes at all? To achieve these goals on the Albanian education, the National Pre-University Education Strategy describes the way that this change would improve the system. Solutions consist in reviewing and studying the changes the system itself has made and if it has brought to better results, as the changing of the syllabus and school texts. Is the Albanian School prepared for this change?
\end{abstract}

Keywords: Curriculum Framework, Albanian Education, Schools Improvement, Implementation of curriculum

\section{Introduction}

In the draft curriculum framework prepared by the IED (Institute of Education Development), the need for reform of curriculum development is seen in the wake of the changes that constantly occure in regional and global level, and as a result of these changes have been reviewed and educational policies that consist in:

- Development of an education-oriented human and moral values

- Taking into account the diverse interests of students

- The continued growth of information

- Communication of the peaceful and successful in a multicultural society

- Improvement of vocational training in order to facilitate the employment and advancement.

Development of basic skills that facilitate adaptation of youth with the changing demands of society are the basis of this new curriculum, aiming at taking responsibility, problem solving and contemporary standards. (izha.edu.al)

Albanian schools comes from a totalitarian system and complete centralization and the need for change is certainly time requirement, but should not be forgotten that these changes will occur precisely on this basis. How committed is our schools for these changes? It is this question which will answer this research and trying to give a detailed overview of the curriculum in general, the situation of Albanian schools as teacher's knowledge on innovations in education.

Should the albanian educational system change in order to adapt to the technological and social development. The change on the curriculum in Albania will be a result of changes but these, the qual conditions include: infrastructure schools, the teachers preparation, traditional mentality etc., in the current educational which system is, might not allow the successful implementation of the new curriculum. What might be some of the obstacles to this? By analyzing the theoretical aspects on the issue and drawing on the views of teachers could be reached at a conclusion regarding the full implementation of the school curriculum series of Albania.

\section{What is a Curriculum?}

Usually planned curriculum, it's presented in a formal written document focuses on the goals, objectives, content and organization of teaching and unplanned informal curriculum has to do with psychological mutual action between students and teachers especially with feelings, attitudes and behaviors them. (Orstein, Hunkins ,2003:20)

Through the curriculum, school culture affects people whom it serves, but similarly, cultures influence and shape the school and its curriculum. Through learning the curriculum, schools can change society, while society and can form school and its curriculum, therefore under development, curriculum development and implementation of significant 
impacts is taken into account the nature and consequences of social and educational purposes.

\section{Historical Basis of the Curriculum}

Bob's scholar book in 1918 (Orstein \&Hunkins, 2003) can be called the field of curriculum strands. In this edition became the epicenter of curriculum knowledge. If you make a presentation to the school curriculum (U.S.) can be said that in the years 1642-1776 was reading the most important subject, followed by writing and penmanship. Should also be noted that in this period the schools adhere to strict principles of theology. In the 1800's, schools began to give importance arithmetic and catechism and over recent school curricula constantly expanded, including grammar, geography, etc. household historical studies.

If we speak Albanian school history course that has leaked otherwise. Creating the first Albanian school in 1887, certainly dates back much later than the opening of schools in many countries and has been though to be models that can be followed. History of Albania conditioned in some way and Albanian school curriculum. The influence of the Italian school in 1924-1944 period, and after the liberation of the Russian school impact was significant as the organization of learning, as well as the methodology followed. The years since 1990 have been for the school year in which the Albanian school is trying to adjust to developments in world education. Many educational reforms in recent years clearly show this.

\section{The Planning and Development of the Curriculum}

Education goals are usually expressed at different levels. Targets are declarations of intent with a result in mind. According Suvellit goals give the response to this question: What destination have in mind for students, in terms of a curriculum or a particular subject? So, when it comes to curriculum goals, should be taken into account students' desired outcomes as a result of curriculum development. Analysis of school goals helps us to determine the limits of its entire curriculum. Objectives derive from goals, and as such they provide teachers and decision-makers a clear curriculum, which should be student achievement by developing a subject or a particular educational program.

What should be included in the teaching? How to apply? How to organize? There are specialists who deal with curriculum knowledge, content, teaching experiences and learning. In selecting content uploaded groups use alternative curriculum planning that affected their philosophical outlooks. Content to be solved is very broad, and while they have to find the meaning of what is available and choose one that will enable students to learn more, regardless of the curriculum to be implemented.

Content is not just the information that is taught in school. It should include data related to students' interests and organized in such a way that they find useful information and deep understanding. When choosing curriculum content, the planner must be careful to treat all content aspects of cognitive, social and psychological as individual students.

\section{Implementation of the Curriculum}

People who wish to implement the new curriculum is needed to understand the nature of the change being considered. What will include school program?

These are two questions that people ask about innovations. People want to know the purpose of the cloud and how it will be accomplished. In most cases the idea is to remember the KISS theory (keep it short and simple)

To accept the new people must perceive the quality, value and practicality of it.

Collection of data that allow planners and implementers of program decisions, made in different ways. In the pilot phase of implementation, can be used different tests, as prepared by business and by teachers to provide data showing how students interact with the new curriculum pilot . Can organize information sessions with teachers, as well as footage of various events that can be analyzed when developing new programs.

Including needs analysis in the overall planning and implementation of curriculum means that can be seen as things are going well.

However, the curriculum determine the content of what students will learn and how to learn and will certainly affects the education of students. The knowledge that they are receiving valuable and suitable for life? How necessary are these insights? Is it is important knowledge (knowledge in vetevte) or and how to proceed? We are all aware that the way of education and what we learn in school success leaves clues at each of us in life. What is required today is not just school knowledge acquisition but also the creation of social skills and adapt to the rapid development of information technology. If the content of the curriculum addresses all aspects of cognitive, social and psychological as individual learners, the official curriculum and it's hidden or unwritten would be serving the general curriculum goals and long- 
service education students.

\section{Aims of the New Curriculum in Albania}

"Pre-university education system aims at the formation of each individual core competencies" (the framework curricula). Group core competences is a very important concept in designing curricula. For the value and impact, competence is the key point, which is posjell innovates and real life education in school.

Article 13 (Law 69/2012 mash.gov.al)-law for university education)) states that: "The activity of the institutions of the education system aims to every student, as a citizen of a democratic society, be equipped with the skills for lifelong learning and possess powers 7 curriculum areas involved in curricular framework, namely the school focuses on creating "long habit of learning."

Construction of key competencies (first, writing, reading and computation) in this age group is decisive for the further progress of each child and is influenced not only by the characteristics of psychological development, but also by factors with strong pedagogical impact, shaped by efforts to better adapt to the new school, social, economic and technological. However, the curriculum based in current structure, where the primary cycle lasts five years, starting early enough doses of abstract thinking, than students in general can,. [Source: http://www.izha.edu.al], have made the change from 5 to $6+3+4$, being so close to the psychological characteristics of students.

Learning standards are organized into several main lines in accordance with levels of education, school to provide important elements for the development of education. To assess the quality of education and to judge the development of children in the relevant field. [Albanian language and literature, foreign languages, natural sciences (biology, physics, chemistry, geography) social science, education, entrepreneurship, arts (visual arts, dance, theater, music), physical education and sports technology]

\section{Need for Curriculum Changes}

With the accession of Albania in the period of rapid change and where each new change triggers a whole chain of events, Blizzard is doing this and most other important. Change of society, advances in science, communications, transportation and the world affect the quality of life and global consequences.

Teachers, curriculum specialists, especially, should reduce educational backwardness and school planning for the new century, do not use the same ways that were appropriate to 20 years ago, ie to avoid the typical lag that exists between schools and society. The fact of rapid change and the need for planning for the next school today we bring before us such questions: - What policies governing society today? What should be our educational goals at the global level? What 'role will play schools in today's time? As schools reduce the gap between the poor and rich? As schools prepare students for the world of tomorrow?

It is precisely these social changes that have çuar successive changes in the school curriculum. Often it seems as if no reform over another begins. Of course such changes requires time, but the change of curriculum should be such that students achieve long-term results, while many former students are already hard to find themselves in the labor market, as we have begun to change not the lower levels (preschool and primary cycle), but higher levels (master and doctorate).

\section{Evaluation of the Curriculum Framework}

In Article 6 of the Draft Law on University Education determined that "the activities of the institutions of university education system, is the primary interest of students." In this regard the transition from 4 to $5+6+3$ aims to decrease the load pupils and students achieve standards comparable to most other European educational systems. In the framework curricula are provided: principles, general aims of the curriculum, cross key skills, areas of learning, crosscutting themes, principles of teaching / learning and assessment. The unification designed to ensure that primary and lower secondary curriculum aimed at boosting this capability to understand and implement written information in everyday life, at home, at work and in the community. (Rev. Ped, 2011)

Manner of submission of curriculum gives a clear indication of the school's goals, as adjusted to school time and that aims to prepare the citizens of tomorrow, but the school is preparing for the implementation of the curriculum?

\section{The Albanians Educational System Readiness for the New Curriculum}

Those who dislike the subject centered models may pay less attention to the learning environment. To no matter where 
learning happens, but now our school aims at teaching over the student run, and it certainly requires enough space (classrooms, gyms, labs, canteens, etc.) and appropriate tools (banks, chairs, etc.). Learning environments to help students in acquiring the knowledge targeted to activities intended to encourage and allow students a depth and variety of activities that facilitate learning and can be said that the majority of Albanian schools do not meet these criteria (starting that the number of students per classroom, spaces for artistic activities, sports targeted by so many new curricula)

The school as an institution of education organized people, up from society, not only for the present but for the future, even anticipating changes that bring development. To us is doing much about it, but from my experience I can say that school traditional teaching is satisfactory and teachers still have somewhat hard to give it up. Perhaps the transition from the source authority, the leader of organizational learning and the learning facilitator is difficult. The new curriculum requires exactly this kind of teaching where the teacher and a teacher to educate the students to lifelong learning.

Teachers and students are the main actors in the implementation of the curriculum. Ç'mendojnë teachers? How prepared they feel about these changes?

To see what were the opinions of teachers about the new curriculum and their knowledge of, a survey was conducted with 25 teachers from schools in Elbasan. Teachers were selected at random. Of these $40 \%$ were teaching in primary education, $40 \%$ in arsimine lower secondary and $20 \%$ in secondary education. Teachers surveyed had more than 5 years experience in the cycle where teaching.

The processing of the data shows that: $84 \%$ of teachers say that there is never required thinking about the design of the curriculum, and $80 \%$ think that the new curriculum is not appropriate for school implemented in Albania, it the fact that conditions are inadequate schools, children may have difficulty in adapting to this new system of education, the number of students in classrooms and school facilities do not allow such a thing, elementary teachers can not afford can teach up to grade 6 , because of the lack of adequate preparation. Many of them felt that this change can bring and reduce jobs.

Since the new curriculum subject integration is seen as a priority the development of learning, one of the questions was precisely the willingness of teachers to work with integrated subject. In this question $50 \%$ of teachers say that they can not realize an integrated teaching. $96 \%$ of teachers agree that in terms of implementation of the new curriculum teachers must have intensive training in order to be clear as to what needs to change, to përvertësuar new practices to implement them successfully .

As evident from the data of surveys conducted, teachers do not see themselves prepared to welcome these changes and work to be done in this direction should be the part of the institutions responsible for the training and qualification of teachers, so that the new curriculum will not remain on paper, but applies to give the expected results. I think that at this stage of the work to be done by the respective institutions for the training of teachers must be very great.

\section{Effects the New Curriculum will have on the Pupils}

For Dewey psychology was the basis for understanding how the student interacts with objects and people in the same environment. This process continues throughout life and quality of interaction determines the amount and type of learning. Given that the various stages of psychological development life is different and goes from a lower stage to a higher draft curriculum and the way certainly takes into account these developments. One of the changes in the new curriculum is the primary switching from 5 to $6+3+4$. This is done by developers of curricula in order to reduce the burden on students. Seen in this aspect should not be forgotten Albanian schools a reality: while the law contains a child who has reached the age of 6 should start first grade, in most cases they start school age 7 or 7 and a half years. This can lead to an imbalance of what is written and what is required in school and really a differentiation of students in lower levels of education, differentiation will become increasingly pronounced in the higher grades, leading to consequently reducing quality.

Children today live in a world of open and democratic. They live in a time of information technology walk with breathtaking speed. In this respect we can say that teacher education should be as close to the experiences of children and women of technology.

Changes occurred in Albania have made a difference and social settings. May already be spoken for children of different communities, which until 90 years not "exist". Albanian family has also undergone major changes. Social classes in these years have changed the differentiation between them have become too big. Children who come from these layers and the need for additional treatments or particular have grown in number in our schools. A curriculum has taken into account these new social development of society? Apparently the curricular framework emphasis was put goals, areas of learning objectives for each area, and little is mentioned comprehensiveness and adaptability. The way we will realize these are unclear. 


\section{Conclusion: The School as a Factor for Change}

Today's society is changing very quickly. To understand social change and how to live with it, namely assistance should be sought from schools, but schools are conservative institutions that normally remain behind the change. Surveys of teachers reinforce this idea. It seems that people are more willing to accept changes than institutional materials. they exhibit resistance to changes in fundamental ideological ideas and difficult to adapt to change the mentality of the time in which they live.

Upon entering our country in the period of rapid change and where new çdo change causes a whole chain of events, the school should be the main institution that not only accept change, but to educate and future citizens, who will face more challenges in life.

One of the problems in drafting mw tw rwndwsishme planning and implementation of new curriculum, according to me is the participation of stakeholders in curriculum design. Despite the claims of school democratization, participation of teachers, students, parents curriculum is scarce.

Another problem is the low level of professional competence on the part of teachers of primary education, and not only creates difficulties in successfully implementing the new curriculum.

It's hard to change what usually makes classroom teacher (simple transmission of knowledge previously worked), despite guidelines issued, targeting school or those who write in their diaries. It is important to change its philosophy, concepts about building knowledge and attitudes about science.

School environments often leave much to be desired, we can mention here the minimum conditions: heat and space for each student, are another difficulty in successfully implementing the new curriculum.

Texts overloaded, exhausting tests also negatively affect students in forming contemporary students. Teachers should already be experts in the selection of textbooks and assessment of students, not all based their work on assessment tests.

So, I think that intensive training of teachers in service, and those prepared in universities is currently very important to change the philosophy of teachers directly affects the successful implementation of the curriculum. Additionally, upgrading the physical environment of schools (learning, recreation, sports and support), would support the success of the new curriculum.

\section{References}

Evelyn J. Sowell, (1996).Curriculum: An Integrative Introduction,Upper Sanddle River, Prentice Hall, Leslie J. Bishop (1976), Staff Development and Instructional Improvement,Boston, Allyn and Bacon,

Micheal Fullan and Alan Pomfret, (1977), Research on Curriculum and Instruction Implementation, Educational research Xhelili, Q.( 2007) Problemet e edukimit, SHBLU, Tiranë

Revista Pedagogjike (2000), Reforma ne Arsimin Parauniversitar, Tiranë

Allan C. Orstein, Francis P. Hunkins (2003) Curriculum, Foundations, Principles and Issues, Botim shqip, Tiranë. Pp 20, pp. 91-115

www.izha.edu.al/materiale/Revista_Pedagogjike_2011.pdf

www.mash.gov.al

The Concept of Hidden Curriculum, Kohlberg and Hidden Curriculum in Moral Education: An Opportunity for Students' Acquisition of Moral Values in the New Turkish Primary Education Curriculum,by Halil Eksi, available athttp://www.academia.edu 